\title{
REPRESENTAÇŌES DE ESCOLA EM UM LIVRO DIDÁTICO DE INGLÊS À LUZ DA GRAMÁTICA DO DESIGN VISUAL
}

\author{
REPRESENTATIONS OF SCHOOL IN AN ENGLISH TEXTBOOK \\ UNDER THE PERSPECTIVE OF THE GRAMMAR OF VISUAL \\ DESIGN
}

Sulany Silveira dos Santos (UEPG)

sulany.santos@gmail.com

Carla Fernanda Stumf Murialdo (UEPG)

carlamurialdo@gmail.com

\begin{abstract}
RESUMO: A Gramática do Design Visual (KRESS; VAN LEEUWEN, 2006 [1996]) aborda o modo semiótico visual com base na linguística sistêmico-funcional (HALLIDAY, 1978; 1985; 2014). Os autores propõem uma análise a partir das metafunções representacional, interativa e composicional. Este artigo analisa imagens de sala de aula presentes na página de abertura da Unidade 4, intitulada Let's Go to School, do volume 1 da coleção Way to English for Brazilian Learners (FRANCO; TAVARES, 2015). Essas imagens representam salas de aula do Brasil, da Alemanha e da Etiópia e foram analisadas nas metafunções interativa e composicional. Os resultados indicam que existe uma gradação de interação entre as imagens e que os elementos composicionais se inter-relacionam de forma a apresentar a escola etiope como a mais distante do leitor e a que inspira menos interação; as imagens também constroem e perpetuam uma visão estereotipada do negro no livro-didático e uma visão eurocêntrica de mundo.
\end{abstract}

PALAVRAS-CHAVE: Gramática do Design Visual; livro didático-inglês; escola.

ABSTRACT: The Grammar of Visual Design (KRESS; VAN LEEUWEN, 2006 [1996]) approaches the visual semiotic mode based on the perspective of systemic-functional linguistics (HALLIDAY, 1978; 1985; 2014). The authors propose a system to analyze images according to the representational, interactive and compositional metafunctions. This paper analyses images of classrooms in the front page of a Unit named Let's Go to School, of volume 1 of the textbook collection Way to English for Brazilian Learners (FRANCO; TAVARES, 2015). Those images represent classrooms from Brazil, Germany and Ethiopia and were analyzed from the perspective of the interactional and compositional metafunctions. The results indicate that there is a gradation in interaction among the images and that the compositional elements interact to present the Ethiopian school as the most distant from the 
reader and the one that builds less interaction; the images also construct and perpetrate a stereotyped vision of the African people in the textbook and a Eurocentric vision of the world.

KEYWORDS: grammar of visual design; English textbook; school.

\section{Introdução}

As imagens presentes em livros didáticos de língua inglesa (LDLI) têm sido estudadas por diferentes pesquisadores a partir de diversas perspectivas teóricas (p. ex. ARAÚJO, 2011; FERREIRA; CAMARGO, 2014). Dentre essas perspectivas, encontra-se a Gramática do Design Visual (GDV) de Kress e Van Leeuwen (1996/2006), que oferece um aparato metodológico para analisar os elementos visuais presentes em imagens. Diferentes estudos empregaram a GDV para análise de imagens presentes no LDLI (ARAÚJO, 2011; ALMEIDA, 2011; HOLANDA, 2013; BARBOSA; ARAÚJO, 2014; CARVALHO; ARAGÃO, 2015; KUMMER, 2015; SILVA, 2016; SILVA; ALMEIDA, 2018; JORGENS, 2018; FERREIRA, 2019). Esses estudos demonstram o potencial da GDV tanto para “desmistificar uma percepção generalizada das imagens enquanto meios de entretenimento desprovidas de significados ideológicos" (ALMEIDA, 2009, p. 177) quanto como um aparato teórico-metodológico capaz de "fundamentar o trabalho do professor de modo que o estudo dos modos de organização dos textos esteja pautado em pressupostos teóricos que concebam as produções imagéticas como constructos culturais e que carregam valores, crenças e ideologias" (FERREIRA, 2019, p. 42).

As pesquisas supracitadas demonstram que o aporte teórico da GDV tem sido amplamente empregado para a análise da linguagem visual, para a investigação da prática pedagógica no que se refere ao letramento visual e também para a proposta de atividades voltadas para esse letramento (ALMEIDA, 2011). É também possível constatar que é consenso entre esses pesquisadores a necessidade de formar professores de inglês como língua estrangeira (ILE) capazes de entender os sistemas de significação empregados no modo imagético a fim de capacitá-los a desenvolver o letramento visual de seus alunos. Nesses estudos, letramento visual é compreendido de acordo com Bamford (2009, p. 1), que o define como:

um conjunto de habilidades necessárias para o sujeito ser capaz de interpretar o conteúdo visual das imagens, examinar o impacto social dessas e discutir o propósito, o público-alvo e direitos autorais das mesmas. Isso inclui a habilidade de 
visualizar internamente, comunicar visualmente, ler e interpretar imagens. Além disso, estudantes devem estar conscientes dos usos de manipulações e implicações ideológicas das imagens.

Em nosso entender, o desenvolvimento do letramento visual inicia-se com o professor conhecendo e analisando criticamente o material didático empregado em sua prática didáticopedagógica. No contexto deste artigo, isso significa conhecer os recursos semióticos empregados para a construção do texto imagético, bem como o potencial ideológico que esses textos carregam. Desse modo, este artigo tem como objetivo analisar as imagens que representam três diferentes contextos escolares, nomeadamente: brasileiro, alemão e etíope, presentes na abertura da Unidade 4, intitulada Let's Go to School, do livro didático do $6^{\circ}$ ano, que integra da coleção Way to English for Brazilian Learners (FRANCO; TAVARES, 2015). A referida coleção faz parte do Programa Nacional do Livro Didático (PNLD) para o período 2017-2019. Os sistemas de representação das metafunções interativa e composicional como propostos na GDV serão empregados para a análise das imagens. Pretendemos demonstrar que o texto imagético, longe de ser mera ilustração em um material didático, é uma produção cultural que pode perpetuar e reforçar estereótipos.

Este artigo está organizado em três seções, além desta Introdução e das Conclusões. Primeiramente, apresentamos a fundamentação teórica da GDV; em seguida, explicamos a metodologia de pesquisa adotada; na sequência, analisamos as imagens a partir dos sistemas que compõem as metafunções interativa e composicional.

\section{A Gramática do Design Visual}

Nesta seção, apresentamos os pressupostos da GDV para abordar textos no modo semiótico visual, especialmente os sistemas de significação das metafunções interativa e composicional, empregadas para a análise das imagens apresentadas neste artigo.

Os proponentes da GDV asseveram que “o que é expresso na língua por meio da escolha entre diferentes classes de palavras e estruturas oracionais pode, na comunicação visual, ser expresso por meio da escolha entre diferentes usos de cores ou diferentes estruturas composicionais" (KRESS; VAN LEEUWEN, 2006, p. 2). Isso não significa, no entanto, que haja equivalência entre as representações verbais e visuais, pois os diferentes modos semióticos possuem diferentes meios de realização. Nesse contexto, a GDV propõe um sistema que descreve as estruturas visuais que compõem os textos imagéticos. Para desenvolver sua gramática, os autores partem dos pressupostos sistêmico-funcionalistas da 
linguagem propostos por Halliday $(1978 ; 1985 ; 2004)$ e apresentam sistemas de significação presentes em imagens, demonstrando que os significados produzidos no texto imagético são "acima de tudo significados sociais" (KRESS; VAN LEEUWEN, 2006, p. 20). Em outras palavras, assim como a gramática proposta pela Linguística Sistêmico-Funcional (LSF) descreve como os elementos da linguagem verbal organizam-se em diferentes sistemas e entende que todo significado é resultado de escolhas sociais e culturalmente situadas, a GDV descreve como elementos de uma imagem se combinam para produzir significados também social e culturalmente situados. Nesse sentido, a GDV situa-se no contexto sociossemiótico de abordagem do signo.

A proposta metodológica da GDV demonstra que as imagens não são veículos neutros, descontextualizados sócio, política e culturalmente, mas além de serem "imbuídos de estruturas sintáticas próprias” (ALMEIDA, 2008, p. 9), "produzem e reproduzem relações sociais, comunicam eventos ou questões e interagem com o espectador com força semelhante à do texto linear, além de serem dotadas de mensagens organizadas e estruturadas independentemente deste." (OLIVEIRA, 2006, p. 21)

O quadro teórico para a análise imagética proposto pela GDV toma como base as metafunções ideacional, interpessoal e textual propostas por Halliday (1994; 2014) na Gramática Sistêmico-Funcional (GSF), empregadas originalmente para a linguagem verbal. Segundo os autores da GDV, todo modo semiótico:

\begin{abstract}
deve ser capaz de representar aspectos do mundo assim como é experimentado pelos seres humanos. Em outras palavras, deve ser capaz de representar objetos e suas relações em um mundo fora do sistema representacional. [...] deve ser capaz de projetar as relações entre o produtor de um signo (complexo) e o receptor/reprodutor daquele signo. Ou seja, qualquer modo deve ser capaz de representar uma relação social particular entre o produtor, o observador e o objeto representado. [...] e deve ser capaz de formar textos, complexos de signos, que são internamente coerentes entre si e externamente com o contexto no qual e para o qual eles foram produzidos. (KRESS; VAN LEEUWEN, 2006, p. 42-43)
\end{abstract}

Para todas essas instâncias de representação, os modos semióticos oferecem uma gama de escolhas, e essas possibilidades são configuradas na GDV, assim como na GSF, em sistemas. Cada modo semiótico tem seus próprios meios de representação; assim, para leitura, análise e produção do modo visual, os autores da GDV propõem sistemas de significação a partir das metafunções representacional, interacional e composicional. A Figura 1 compara as metafunções da GSF com as propostas pelos autores da gramática visual. 


\begin{tabular}{|c|c|c|}
\hline$\overline{\text { GSF }}$ & GDV & \\
\hline $\begin{array}{l}\text { Ideacional } \\
\text { (Léxico-gramática) }\end{array}$ & $\begin{array}{l}\text { Representacional } \\
\text { (Intra-imagem) }\end{array}$ & $\begin{array}{l}\text { Estruturas visuais que constroem visualmente a natureza } \\
\text { dos eventos, objetos, participantes envolvidos e as } \\
\text { circunstâncias em que ocorrem; estabelecem as relações } \\
\text { construídas entre os elementos retratados. }\end{array}$ \\
\hline $\begin{array}{l}\text { Interpessoal } \\
\text { (relações sociais) }\end{array}$ & $\begin{array}{l}\text { Interativa } \\
\text { (inter-imagem) }\end{array}$ & $\begin{array}{l}\text { Estruturas visuais responsáveis pela relaçãoentre os } \\
\text { participantes estabelecem a natureza da relação entre } \\
\text { quem vê e o que está sendo visto. }\end{array}$ \\
\hline $\begin{array}{l}\text { Textual } \\
\text { (estruturação } \\
\text { mensagem) }\end{array}$ & $\begin{array}{l}\text { Composicional } \\
\text { (inter-modal) }\end{array}$ & $\begin{array}{l}\text { Estruturas visuais responsáveis pelo formato do texto e } \\
\text { pela disposição dos elementos, estabelecendo o valor } \\
\text { hierárquico dos elementos na imagem e entre os } \\
\text { diferentes modos de representação da informação } \\
\text { (multimodalidade). }\end{array}$ \\
\hline
\end{tabular}

Figura 1 - Comparação entre as metafunções da GSF e da GDV

Fonte: Lovato (2010, p. 117)

Os três significados são construídos simultaneamente no texto, que é concebido como um todo resultante das três instâncias de significação, entretanto é possível analisar os sentidos construídos por um texto imagético a partir de uma das metafunções, dependendo dos objetivos da pesquisa.

Na sequência, apresentamos os sistemas que compõem as metafunções interativa e composicional, empregadas para análise das imagens no presente trabalho.

\section{A metafunção interativa}

As relações ou interações entre o observador de uma imagem e aquilo que é representado imageticamente - objetos, pessoas, lugares - são instanciadas por meio das estruturas visuais da metafunção interativa. Essa interação envolve três diferentes participantes, nomeadamente: o observador ou leitor, denominado de participante interativo (PI); o(s) elemento(s) presente(s) na estrutura imagética, ou participante representado (PR); e o produtor da imagem. Os autores da GDV propõem que o processo interativo entre o 
observador e o elemento representado na imagem seja analisado a partir de quatro dimensões: contato, enquadramento, perspectiva e modalidade ${ }^{l}$.

O contato revela maior ou menor interação entre o PI e o PR e é representado por meio do olhar do PR, que pode ser de demanda ou de oferta. No contato por demanda, o PR olha diretamente para o PI, endereçando-lhe um você visual, demandando algo de seu leitor. Nesse caso, entende-se que a intenção do produtor da imagem é de criar um vínculo direto entre PI e PR. "O olhar do PR (e de um gesto, caso esteja também presente) [...] demanda que o PI entre em uma relação imaginária" com o PR (KRESS; VAN LEEUWEN, 2006, p. 118). O olhar, o sorriso, a expressão facial ou um gesto presentes na imagem caracterizam uma comunicação irigida ao PI, demandando dele uma relação peculiar de afinidade social. Os autores acrescentam ainda que o contato visual de demanda pode ser subdividido em diferentes tipos quando combinados com outros elementos visuais. Assim, o contato visual de “convite”, por exemplo, é uma imagem na qual o PR também está com a mão acenando e um sorriso em seu rosto; o de "convocação", por outro lado, é realizado quando o PR acena com a mão e esboça um sorriso; já no contato visual de "aviso/advertência" o PR aparece com um dedo levantado, apontando em direção ao PI, e uma expressão facial severa.

No contato por oferta, o PR representado na imagem direciona-se ao PI indiretamente; não há contato visual, “o papel do espectador é o de um observador invisível [...] e a imagem oferece os participantes representados como item de informação, objetos de contemplação, impessoalmente, como se eles fossem espécimes em uma vitrine" (KRESS; VAN LEEUWEN, 2006, p. 119).

A segunda dimensão proposta para as estruturas visuais que constroem interação é a distância social, que é realizada pelo enquadramento dos elementos representados na imagem. Esse enquadramento pode ser de plano fechado, plano médio ou plano aberto e determina uma relação social imaginária de maior ou menor distanciamento entre PI e PR, representando as pessoas, por exemplo, em uma relação de amigos ou de estranhos. Quanto maior o enquadramento ou o distanciamento do PR na imagem, menor será a interação criada com o PI. Por outro lado, quanto mais próximo o PR é apresentado, maior será o nível de interação criado entre ele e o PI. Esses planos são representados em um contínuo a partir do enquadramento que se dá ao corpo humano na imagem. Com base em Kress e van Leeuwen, Harrisson (2003, p. 51) apresenta seis possibilidades de distância criada entre PR e PI.

\footnotetext{
${ }^{1} \mathrm{Na}$ análise que fazemos das imagens neste artigo, nossa decisão metodológica foi não analisar a dimensão modalidade, tendo em vista que todas as imagens são naturalistas e apresentam alta modalidade (KRESS e VAN LEEUWEN, 2006, p. 166).
} 
Adaptamos a proposta de Harrisson incluindo o que os autores da GDV mencionam sobre os planos.

\begin{tabular}{|l|l|l|}
\hline \multicolumn{1}{|c|}{ Distância social } & \multicolumn{1}{c|}{ Plano } & Como o PR é retratado \\
\hline íntima & plano fechado extremo & somente a cabeça e a face \\
\hline Pessoal próxima & plano fechado & somente a cabeça e ombros \\
\hline pessoal longa & plano fechado médio & da cintura para cima \\
\hline social próxima & & até os joelhos \\
\hline Social próxima & plano médio aberto & todo o corpo \\
\hline social longa & plano médio aberto & todo o corpo e o espaço ao seu redor \\
\hline Pública/impessoal & plano longo aberto & o torso de muitas pessoas \\
\hline
\end{tabular}

Figura 2 - Possibilidades de Distância Social

Fonte: elaborada pelas autoras

Quando a intenção do produtor da imagem é criar maior envolvimento entre o PI e o $\mathrm{PR}$, a imagem terá maior aproximação no enquadramento, isto é, uma imagem em plano fechado construirá menos distanciamento social entre os participantes, e vice-versa (SILVA; ALMEIDA, 2018).

A perspectiva é a terceira dimensão que determina a representação da interação entre os participantes de uma imagem. Ela "indica uma atitude mais ou menos subjetiva por parte do produtor da imagem em relação aos participantes" (SILVA, 2016, p. 72) e é expressa por meio deum ângulo particular, ou ponto de vista. Nas culturas ocidentais, as imagens podem ser objetivas ou subjetivas; imagens objetivas não têm perspectiva e consequentemente não apresentam um ponto de vista interno, revelam ao PI tudo o que pode ser revelado do PR. Elas desconsideram o PI, é como se dissessem: "Eu sou assim, independente de quem você é ou de onde ou do tempo em que você se encontra" (KRESS; VAN LEEUWEN, 2006, p. 131). Um exemplo são os manuais de instrução nos quais as peças de uma máquina são retratadas “como elas são". As imagens subjetivas, por sua vez, são imagens com perspectiva e com um ponto de vista interno intrínseco que mostram o PR ao PI somente a partir de um ponto de vista específico, que foi escolhido para ser mostrado.

Ainda na dimensão perspectiva, as imagens podem ser retratadas a partir dos ângulos horizontal ou vertical. Por meio do ângulo horizontal constroem-se relações de envolvimento, entre o PI e o PR; por outro lado, o ângulo vertical possibilita a construção de relações de poder entre ambos. Em relação ao envolvimento, uma imagem pode ser retratada do ângulo 
frontal ou oblíquo. No ângulo frontal, o PR é apresentado frontalmente para o PI; nesse caso o PR é mostrado como "um de nós", cria-se maior envolvimento entre PI e PR. No ângulo oblíquo, por sua vez, o PR é representado obliquamente para o PI, criando afastamento entre os participantes, o PR é representado como "um deles".

O ângulo vertical, por outro lado, cria relações de poder entre o PI e o PR. A representação de uma imagem de baixo para cima é realizada a partir de um ângulo alto, o PR configura-se como alguém que detém mais poder do que o PI, nas palavras de Kress e Van Leeuwen (2006, p. 140), “ele parece imponente e incrível". Por outro lado, quando a imagem do PR é retratada de cima para baixo, confere-se mais poder ao PI do que ao PR, pois esse ângulo faz com que o sujeito pareça "pequeno e insignificante" (KRESS; VAN LEEUWEN, 2006, p. 140). Finalmente, uma relação de poder de igualdade é criada quando o PI e o PR estão no mesmo nível, isto é, na mesma altura, no nível dos olhos.

A quarta e última dimensão empregada para construir interação é a modalidade e refere-se à verossimilhança de uma imagem. Na análise que fazemos das imagens neste artigo, não analisaremos essa dimensão.

\section{A metafunção composicional}

Na metafunção composicional, encontram-se “estruturas visuais responsáveis pelo formato do texto e pela disposição dos elementos, estabelecendo o valor hierárquico dos elementos na imagem e entre os diferentes modos de representação da informação (multimodalidade)" (LOVATO, 2010, p. 118). Essa metafunção dispõe de três subcategorias: valor da informação, saliência e estruturação (moldura). O valor da informação está relacionado à disposição dos elementos na composição da imagem e pode ser descrito em termos de lados esquerdo e direito, parte de cima e parte de baixo de imagem, bem como centro e margem, como ilustrado na Figura 3. 


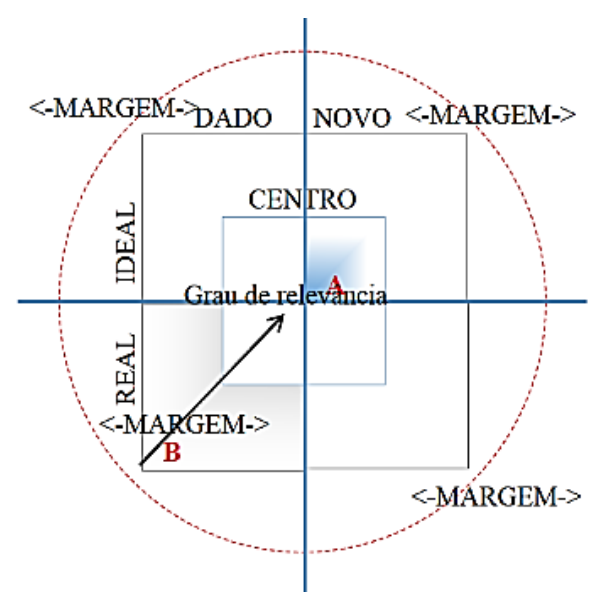

Figura 3 - Valor informativo da imagem

Fonte: Silva e Almeida (2018, p. 53)

O lado esquerdo representa a informação dada, aquela já conhecida do leitor; o lado direito, por sua vez, representa a informação nova. Há também diferenciação entre informação ideal, localizada no topo da imagem, e a informação real, posicionada na parte inferior da imagem. A informação ideal significa a promessa ou o que pode ser; já a informação real retrata o produto e o que ele de fato é. Por fim, na oposição centro/margem, os elementos posicionados no centro representam a informação mais importante, enquanto os elementos dispostos nas margens possuem valor de informação complementar em relação àquela do centro. "Portanto, o que está no centro será o núcleo da mensagem e os elementos marginais terão menor valor, sendo considerados como subordinados ao elemento principal" (SILVA; ALMEIDA, 2018, p. 53).

A segunda subcategoria dessa metafunção é a saliência, que descreve de que forma elementos como tamanho, perspectiva, primeiro e segundo planos, contrastes de cores e diferenças de brilho são organizados na imagem de modo a se tornarem mais ou menos salientes e, assim, despertar a atenção do leitor.

A moldura é a terceira subcategoria que integra a metafunção composicional. Ela retrata como os elementos presentes em uma imagem podem ser interligados ou separados uns dos outros. Essa subcategoria realiza-se de várias formas como a presença de linhas, diferenças de cores, espaços vazios entre os elementos e vetores. Segundo Kress e Van Leeuwen (2006, p. 203), "quanto mais forte a moldura de um elemento, mais ele é apresentado como uma unidade separada de informação". Os autores salientam ainda que:

os membros de um grupo [...] podem ser mostrados em uma imagem de grupo. [...] a ausência de moldura enfatiza a identidade de grupo, sua presença significa individualidade e diferenciação. [...] quanto mais os elementos da composição 
espacial estiverem conectados, mais eles são representados como pertencentes um ao outro, como uma unidade única de informação. (KRESS; VAN LEEUWEN, 2006, p. 203-204).

É importante notar que a metafunção composicional na GDV, à semelhança da metafunção textual relacionada ao texto escrito proposta pela GSF, trata da organização das outras duas metafunções, representacional e interativa. Na sequência, apresentamos a metodologia empregada neste estudo.

\section{Metodologia}

Esta pesquisa é de natureza qualitativa e interpretativa (LAKATOS; MARCONI, 1992), parte da observação e análise de imagens dentro de seu contexto particular e as interpreta a partir de um referencial teórico específico. O estudo é indutivo, uma vez que não partimos de nenhuma hipótese sobre os dados.

A pergunta que esta pesquisa procurou responder foi "como as estruturas visuais interativas e composicionais presentes em imagens na abertura de uma Unidade de LDLI cujo tópico é a vida escolar permitem construir diferentes representações de escola localizadas em diferentes continentes?" O corpus foi composto de três imagens presentes na abertura da Unidade 4, intitulada Let's Go to School, do volume 1 do livro didático de inglês Way to English for Brazilian Learners (FRANCO; TAVARES, 2015). A referida obra foi empregada como objeto de análise tendo em vista o interesse de uma das autoras deste artigo em incorporar em sua prática pedagógica a leitura de textos imagéticos e também pelo fato de essa obra ser o principal material didático empregado em suas aulas de língua inglesa em uma escola pública, localizada no estado do Paraná.

As imagens analisadas fazem parte de um grupo de cinco imagens que representam diferentes escolas no mundo por meio de um grupo de alunos em suas respectivas salas de aula. A primeira imagem analisada representa alunos/sala de aula do Brasil; a segunda imagem analisada representa alunos/sala de aula da Alemanha e a terceira imagem analisada representa alunos/sala de aula da Etiópia. É importante mencionar que optamos por analisar essas imagens porque nosso interesse foi contrastar, no livro-didático em foco, as imagens de escolas localizadas em diferentes continentes. Adicionalmente, nosso interesse de pesquisa focalizou-se nos elementos imagéticos contato, enquadramento e perspectiva, que constroem interação e nas estruturas visuais responsáveis pela composição dos elementos presentes nas imagens. 


\section{Análise e discussão dos dados}

A análise empreendida é orientada com vistas a responder a pergunta de pesquisa: “como as estruturas visuais interativas e composicionais presentes em imagens na abertura de uma Unidade de LDLI cujo tópico é a vida escolar permitem construir diferentes representações de escolas localizadas em diferentes continentes?" Tendo em vista nossa pergunta de pesquisa, as imagens foram analisadas primeiramente a partir da metafunção interativa e, logo após, a partir da metafunção composicional ${ }^{2}$.

As páginas de abertura da Unidade em análise são compostas de textos imagéticosque retratam cenas de alunos em salas de aula de diferentes países e são empregadas para uma atividade de Warm-up (Introdução do tópico) a partir de duas perguntas norteadoras: (1) “As fotos mostram escolas em diferentes países. Qual dessas salas de aula é a mais parecida com a sua? Por quê?” (2) “Qual é a sua disciplina favorita? Por quê?” Encontram-se nessas paginas também cinco objetivos da Unidade, nomeadamente: to talk about your school and get to know different schools around the world (falar sobre sua escola e conhecer diferentes escolas ao redor do mundo); to review the use of verb to be -affirmative, negative and interrogative forms (revisar o emprego do verbo to be nas formas afirmativa, negativa e interrrogativa); to learn how to use the question words (aprender a usar os pronomes interrogativos); to explore school timetables (explorar horários escolares) e, finalmente, to establish connections with Arts, History and Portuguese (estabelecer conexões com Arte, História e Português).

É importante notar que a discussão sobre as imagens presentes nas páginas de abertura da Unidade não são retomadas em nenhuma atividade posterior e que a parte do primeiro objetivo "conhecer diferentes escolas ao redor do mundo" é desenvolvida a partir de tarefas que comparam horários (school timetables) de diferentes escolas.

\footnotetext{
${ }^{2} \mathrm{~A}$ análise das imagens a partir da metafunção representacional não foi realizada, pois nosso objetivo foi averiguar a construção da interação entre o PI o PR, bem como os elementos composicionais que constituem as imagens. À primeira vista, são imagens semelhantes, pois todas apresentam um grupo de alunos em sala de aula, contudo partimos do pressuposto de que a análise das estruturas interativas e composicionais podem apontar diferenças significativas entre as imagens.
} 


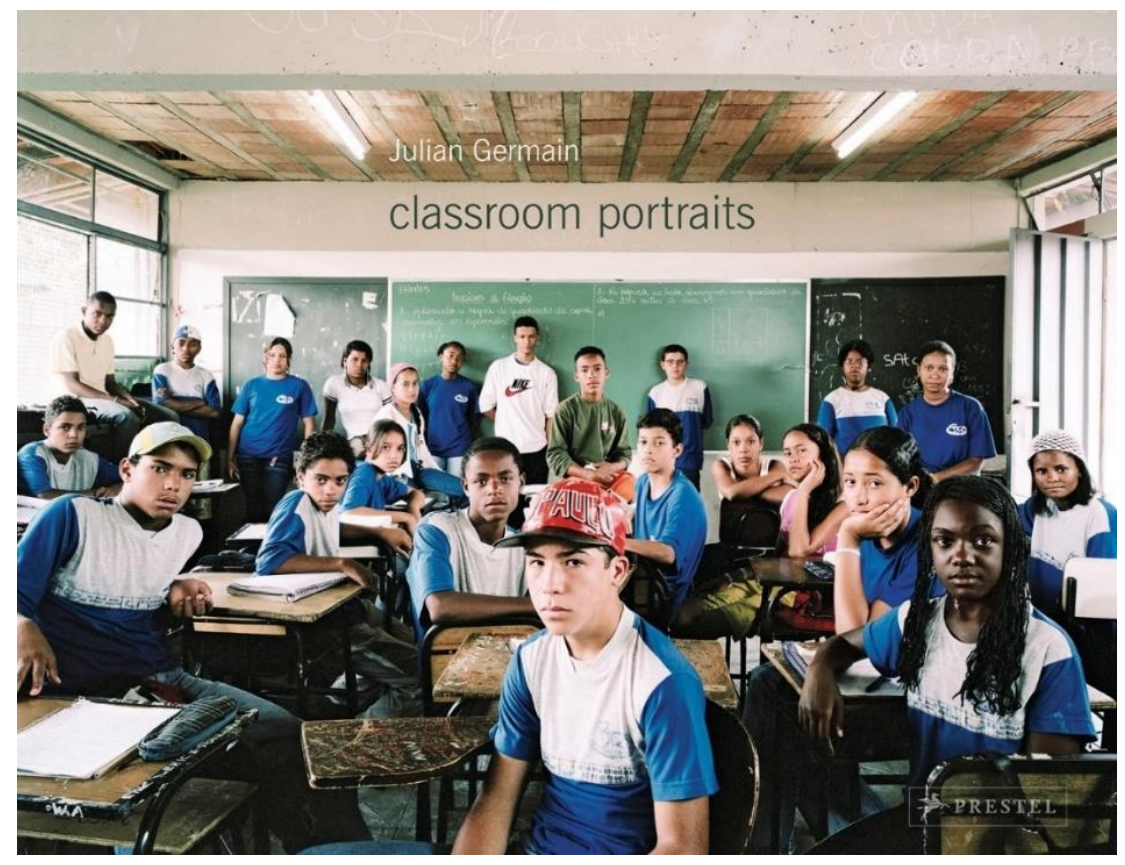

Figura 4 - Sala de aula de uma escola do Brasil

Fonte: Franco e Tavares (2015, p. 61)

Os alunos presentes na Figura 4 são, em sua grande maioria, negros e pardos, com exceção do que aparece em destaque em primeiro plano da imagem e alguns alunos localizados mais ao fundo na sala, os quais caracterizamos como pertencentes à raça branca. Com relação à metafunção interativa, o participante representado (PR) nessa imagem pode ser analisado, por um lado, a partir do grupo como um todo e, por outro lado, a partir dos alunos em destaque em primeiro plano. Quanto ao contato visual, o olhar do PR como grupo é de demanda, olha diretamente para o PI. Nenhum aluno esboça sorriso em sua face e o estudante localizado em primeiro plano na imagem, juntamente com os alunos que o rodeiam, estão com o olhar e expressão facial sérios. Esses fatores levam-nos a concluir que a relação construída entre PR e PI é de distanciamento, inspira pouca interação entre ambos.

No que se refere ao enquadramento e à distância social construída entre PR e PI, observa-se que uma parte do grupo de alunos está sentada, retratada da cintura para cima, enquanto o corpo dos alunos que estão no fundo da sala é retratado dos joelhos para cima. Vemos também que é retratado o espaço ao redor dos alunos que estão ao fundo da sala. Esse enquadramento promove maior distanciamento social entre o PI e os alunos ao fundo da sala, mas menor distanciamento social entre o PI e os alunos em destaque, localizados no primeiro plano da imagem.

Quanto à perspectiva e às relações de envolvimento e de poder, o ângulo horizontal constrói relação de maior envolvimento com o PR (como um grupo), enquanto o ângulo 
vertical, que retrata o PR na altura dos olhos do PI, constrói relação igualitária de poder. Esses aspectos caracterizam o PI como pertencente ao PR como grupo.

Com relação à metafunção composicional, que considera o posicionamento dos elementos imagéticos e a relação entre esses para a construção do significado, observa-se que o PR está no espaço do "real" (parte inferior da foto), indicando a realidade de uma escola brasileira com um número significativo de alunos em sala de aula. Observamos também que os alunos localizados no centro da imagem, em contrate ao restante dos alunos localizados mais ao fundo e às margens, recebem maior destaque. Para a construção da saliência desses alunos em destaque são empregados elementos como o tamanho maior de sua imagem em relação à dos outros alunos, seu posicionamento em primeiro plano na imagem e a cor vermelha do boné do aluno posicionado no centro da imagem. Mais especificamente, observa que as cores azul e branco, predominantes no uniforme dos alunos, constroem uniformidade e podem retratar que todos são iguais, independentemente de cor de pele ou classe social. No entanto, a cor vermelha do boné do aluno que está em primeiro plano serve como um elemento que quebra a harmonia construída pelas cores do uniforme dos alunos, ao mesmo tempo em que lhe confere destaque como, possivelmente, o líder do grupo.

Quanto à categoria moldura, observa-se que não há elementos como linhas, nem espaços vazios que separemos elementos entre o PR; a inexistência desses elementos contribui para a criação de conexão e proximidade entre os elementos constitutivos da imagem, sugerindo afinidade e identidade do grupo. Em outras palavras, os elementos constitutivos da imagem, a proximidade entre eles e a mesma expressão facial representam união e identidade do grupo.

No que diz respeito à iluminação, vemos duas fontes de luz, uma no teto da sala de aula e outra vinda das janelas, localizadas à direita e à esquerda da imagem. Todos os elementos do PR, bem como o entorno da sala de aula recebem iluminação igual. A sala de aula pode ser vista como um ambiente escolar leve e agradável. 


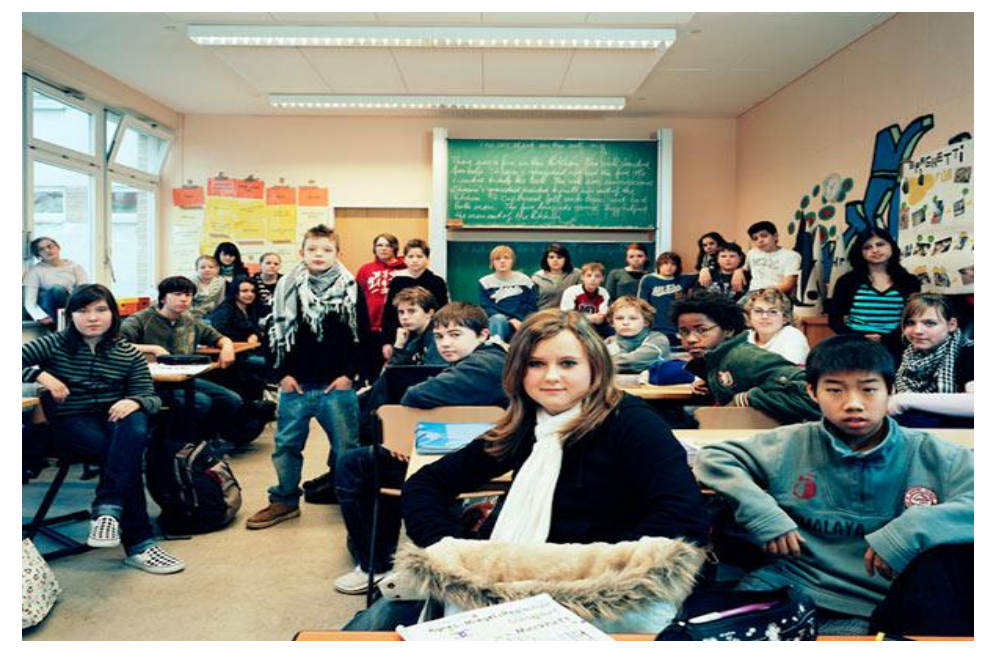

Figura 5 - Escola da Alemanha

Fonte: Franco e Tavares (2015, p. 62)

A grande maioria dos alunos que compõem o PR na Figura 5 são da raça branca, mas vê-se um aluno um asiático e outro da raça negra. No tocante à metafunção interativa, assim como na Figura 4, o PR nesta imagem da escola alemã pode ser analisado, por um lado, a partir do grupo como um todo e, por outro lado, a partir dos alunos em destaque em primeiro plano. No que diz respeito à categoria contato, o olhar do PR como grupo é de demanda, pois olha diretamente para o PI, convidando-o para interagir. A aluna em destaque, com echarpe branca, em primeiro plano da imagem, e mais alguns alunos na parte direita da imagem esboçam um sorriso em sua face. Esses fatores levam-nos a concluir que a imagem convida o PI a construir uma relação de afinidade com o PR.

Quanto ao enquadramento e à distância social que se constrói entre PR e PI, observase que parte do grupo que compõe o PR está sentada, retratada da cintura para cima, enquanto um aluno em pé na parte esquerda da imagem, bem como alguns alunos à sua esquerda são retratados de corpo inteiro. Além disso, o espaço ao redor desse segundo grupo de alunos também é retratado. Esses elementos colaboram para construir uma distância social longa entre o PI e esse último grupo de alunos. Entretanto, à semelhança da imagem da escola brasileira, o enquadramento em plano fechado médio dos alunos em primeiro plano na imagem permite que se construa uma distância pessoal entre o PI e o PR.

Quanto à perspectiva e às relações de envolvimento e de poder, observa-se que o ângulo horizontal frontal caracteriza uma relação de envolvimento com o PR enquanto grupo, ao passo que o ângulo vertical, que coloca esse PR na altura dos olhos do PI, estabelece uma relação igualitária de poder, transmitindo ao PI a impressão de pertencimento ao grupo, de "ser um de nós". 
Com relação à metafunção composicional, ou seja, o posicionamento dos elementos visuais na construção da imagem e a relação entre eles, observa-se que o PR como grupo está no espaço do "real", isto é, na parte inferior da imagem, sugerindo a realidade de uma escola alemã com um número significativo de alunos em sala. Adicionalmente, é dada maior importância aos dois alunos posicionados no centro da imagem em oposição ao restante dos alunos localizados mais ao fundo e às margens da imagem. A posição de destaque dada àqueles dois alunos é ainda corroborada por meio de dois elementos composicionais, quais sejam, (1) o tamanho maior da imagem desses alunos em comparação aos outros alunos; e (2) seu posicionamento em primeiro plano na imagem em oposição aos outros alunos colocados em segundo plano.

Ainda quanto à construção da saliência, observa-se uma diversidade de cores nessa imagem, especialmente nas paredes da sala de aula; a diversidade também é construída pelo lenço que usa o aluno que está em pé e pela presença de um aluno da raça negra e um asiático. Ainda em relação à cor, a echarpe branca da aluna em destaque em primeiro plano contribui para tornar essa estudante o ponto focal da imagem, atraindo a atenção do PI.

Quanto à categoria moldura, observa-se que há uma conexão e proximidade entre os elementos constitutivos da imagem, sugerindo afinidade e identidade do grupo. Mais especificamente não há elementos como linhas, nem diferenças significativas de cores, nem espaços vazios que separe elementos do PR.

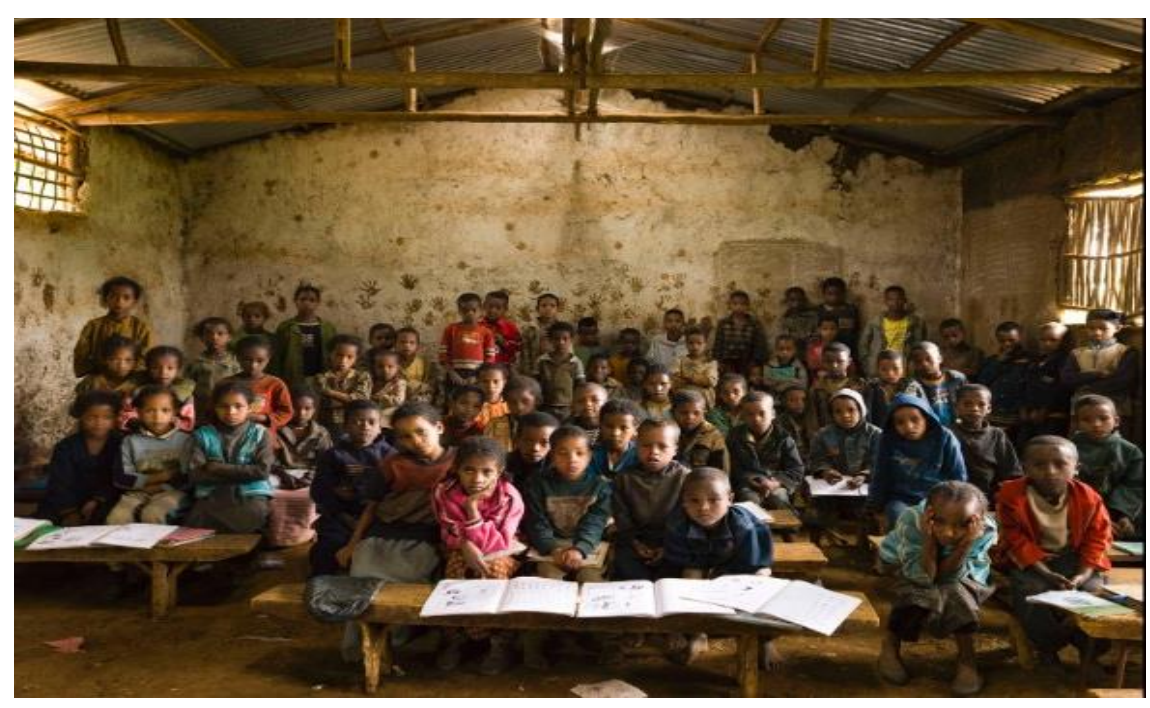

Figura 6 - Escola da Etiópia

Fonte: Franco e Tavares (2015, p. 62) 
Todos os alunos que constituem o PR na Figura 6 são da raça negra. No tocante à metafunção interativa, o PR nesta imagem pode ser analisado, por um lado, a partir do grupo como um todo e, por outro lado, a partir do grupo de alunos em relativo destaque em primeiro plano. No que diz respeito à categoria contato, apesar do PR como grupo olhar diretamente para o PI, o que caracteriza um convite para interagir, o fato de nenhum aluno estar sorrindo permite construir uma relação social de pouca afinidade e de maior distanciamento com o PI. Essa interpretação é corroborada pela distância social construída entre o PR e o PI por meio do enquadramento a partir de um plano médio aberto. Mais especificamente, o fato de serem retratados todo o corpo dos alunos que constituem o PR e o espaço ao seu redor contribui para que seja criada uma distância social longa, impessoal, entre PR e PI, sugerindo menos proximidade entre ambos, representando-os como estranhos um ao outro.

Quanto à perspectiva e às relações de envolvimento e de poder, observa-se que o ângulo horizontal frontal sugere uma relação de envolvimento, contudo o ângulo vertical, que retrata o PR de cima para baixo, caracteriza uma relação de superioridade do PI em relação ao PR. Esses elementos constitutivos da imagem demandam do PI uma atitude de observação, contemplação, e retratam o PR como exótico, distante.

Com relação à metafunção composicional, que permite analisar o posicionamento dos elementos visuais e como esses se relacionam, observa-se que o PR está na parte inferior da imagem, espaço do real, sugerindo a realidade de uma escola da Etiópia com instalações rudimentares e um grande número de alunos em sala de aula. Observa-se também que o objeto material didático recebe destaque pelas seguintes razões: (1) o fato de estar localizado no centro da imagem, (2) por meio da luminosidade que incide sobre ele, (3) por estar colocado em primeiro plano, (4) por ser representado na cor branca em contrate com as cores mais escuras na imagem e, finalmente (5), por estar representado em tamanho maior em comparação a todos os alunos que compõem o PR como grupo. Desse modo, nessa imagem, o objeto torna-se o ponto focal, que atrai atenção do PI.

Quanto à construção da saliência, observa-se uma diversidade de cores, especialmente nas roupas que os alunos vestem, sugerindo diversidade. A cor predominante da sala de aula é sépia, e o fato de essa cor predominar no entorno dos alunos sugere que eles estão envoltos em um ambiente sombrio. Quanto à iluminação, observa-se que há duas fontes, ou seja, uma no teto da sala de aula, que ilumina principalmente a parede do fundo e não os estudantes; a outra fonte de luz ilumina o grupo do PR colocado em primeiro plano na imagem juntamente com o material didático. Observa-se também que há um grupo de alunos à direita e ao fundo da sala que estão nas sombras, sem qualquer iluminação. Entendemos que esses aspectos 
contribuem para conferir maior importância ao material didático em oposição ao PR como grupo e constroem um ambiente escolar pesado e sombrio.

No que diz respeito à categoria moldura, a ausência de elementos como linhas, diferenças significativas de cores, e espaços vazios que separem e destaquem elementos entre o PR como um todo contribui para construir conexão e proximidade entre os elementos constitutivos da imagem, sugerindo afinidade e identidade do grupo.

\section{Comparação entre as imagens}

Neste item comparamos as imagens das três escolas a partir dos elementos semióticos que permitem construir interação e dos elementos semióticos composicionais que permitem posicionar os elementos visuais das imagens a fim de conferir-lhes destaque e importância. As imagens analisadas neste artigo apresentam elementos semióticos comuns que as aproximam, bem como elementos semióticos que as distanciam. No que concerne à interação, a comparação entre os elementos presentes nas imagens permite-nos construir uma gradação entre elas. Mais especificamente, a imagem da escola alemã é a que constrói maior interação e proximidade entre o PR e o PI; seguida da escola brasileira e, finalmente, da escola etíope, que constrói a menor interação e o maior distanciamento entre o PR e o PI. O maior distanciamento da escola africana em comparação às outras escolas é construído especialmente pelo plano longo do enquadramento e pelo ângulo vertical alto, que posiciona os alunos etíopes em uma relação inferior de poder com o PI. Esse ângulo também contribui para que o PI observe o PR de longe e não seja considerado como membro do grupo, "como um de nós".

Em contrapartida, ao compararmos somente as escolas alemã e brasileira, percebemos que maior interação com o PI é construída pela imagem da escola alemã, especialmente por meio do sorriso presente no rosto da aluna posicionada em primeiro plano na imagem. Por outro lado, a ausência de sorriso na face de todos os alunos que constituem o PR da escola brasileira contribui para a construção de menor afinidade com o PI. Quanto à distância social que se constrói em ambas as imagens, observamos que em ambas o PR e o PI são colocados em uma distância social pessoal. Mais especificamente, essa relação é construída pelo enquadramento em plano fechado médio dos alunos em primeiro plano nas imagens, retratados da cintura para cima. Da mesma forma, as relações de envolvimento e de poder são construídas de forma semelhante nas duas imagens. O ângulo horizontal frontal e o ângulo vertical, que posicionam o PI na mesma altura do PR, contribuem para construir relações de 
maior envolvimento, retratando o PI como pertencente ao grupo, "como um de nós", bem como em relação de poder igualitária.

Quanto à metafunção composicional, observamos características semelhantes às encontradas na metafunção interativa; em outras palavras, as escolas alemãs e brasileira são representadas de forma semelhante, enquanto a escola etíope se diferencia de ambas. Nas três imagens, o PR é constituído de um grupo de alunos colocado no centro e em primeiro plano, e de outro grupo de alunos colocado em segundo plano. Os principais elementos semióticos que distanciam a escola etíope das outras escolas são os alunos colocados em primeiro plano e o tamanho dos elementos visuais que constituem o PR. Mais especificamente, o grupo de alunos da escola do Brasil e da escola da Alemanha, bem como as cores vermelha do boné de um aluno e a cor branca da echarpe da aluna em destaque na escola alemã contribuem para posicioná-los como o foco central na imagem, atraindo a atenção do PI para eles. Em contrapartida, na imagem da escola etíope, é dado destaque ao objeto 'material didático', que está posicionado à frente do grupo de alunos colocados em primeiro plano. Em nosso entendimento, esse fato confere maior saliência e importância ao objeto do que ao elemento humano nessa imagem.

As cores branca e azul, bem como a iluminação presentes nas imagens sugerem um ambiente harmônico nas escolas do Brasil e da Alemanha e contrastam com a cor sépia predominante no entorno dos alunos na escola etíope e com a pouca iluminação existente na sala de aula. Em nossa opinião, esses elementos sugerem um ambiente agradável e leve nas escolas alemã e brasileira em oposição a um ambiente pesado e sombrio na escola etíope. Outro elemento que permite conferir pouca importância aos alunos da escola etíope em oposição aos alunos das outras escolas é o tamanho da imagem desses. Mais especificamente, todos os alunos da escola etíope são retratados em um tamanho menor em comparação com os alunos das outras escolas. Contribui também para essa composição o enquadramento do PR da escola etíope em um plano médio aberto, que os retrata a uma distância longa do PI, convidando esse para observar o PR de longe, como algo exótico, desconhecido, distante.

Ao comparamos somente as escolas alemã e brasileira, observamos que a diferença entre elas no que diz respeito aos elementos semióticos composicionais deve-se especialmente à diversidade maior representada na escola alemã em oposição à escola brasileira. Essa diversidade é construída por meio de maior presença de cores diferentes na escola alemã em oposição à escola brasileira.

Em suma, os elementos composicionais presentes nas três imagens indicam que há uma gradação hierárquica entre as escolas, nomeadamente: os elementos presentes na imagem 
da escola alemã conferem maior saliência a essa escola e aos seus alunos; seguida da escola do Brasil e, por fim, da escola etíope.

Os elementos semióticos presentes no texto imagético inter-relacionam-se de forma complexa para construir interação e hierarquia, bem como para atribuir importância aos elementos nele representados. A análise e comparação das imagens de escolas apresentadas neste estudo levam-nos a concluir que essas imagens corroboram a apresentação estereotipada do negro no livro-didático, denunciada por muitos pesquisadores brasileiros, além de contribuir para perpetuar estereótipos relacionados à visão eurocêntrica de mundo (SHOHAT; STAM, 2006).

Pesquisadores como Ferreira e Camargo (2014), Silva (2015) e Müller (2015), dentre muitos outros, têm demonstrado que o material didático privilegia "aspectos recorrentes sobre fome, doenças, guerras e conflitos políticos, a precariedade de vida das populações africanas, no período imperialista [...]" (MULLER, 2015, p. 13). Além disso, as imagens de pessoas negras em livros-didáticos contribuem para reproduzir conceitos e valores de grupos que dominam a sociedade. Alguns desses aspectos podem ser identificados na imagem da escola etíope; mais especificamente, a escola é representada como precária e o PR é diminuído, desempoderado e representado como o mais distante do PI dentre as três imagens.

Como mencionado, observamos também nessas imagens uma visão eurocêntrica de mundo, que destaca os países europeus como centros de referência, mais desenvolvidos econômica e culturalmente em relação aos países não-europeus. Nas palavras de Shohat e Stam (2006, p. 20), o eurocentrismo "vê a Europa [...]como o centro de gravidade do mundo". Em contrapartida, essa visão tende a desvalorizar os contextos de países não europeus, colocando-os em posição de inferioridade em relação aos europeus. $\mathrm{O}$ fato de a escola alemã construir maior interação com o PI, seguido da escola brasileira e da escola etíope, além da relação dos elementos composicionais presentes nessa ultima imagem contribuírem para que a atenção do PI seja colocada, prioritariamente, no material didático em destaque e não nos alunos leva-nos a identificar uma desvalorização e inferiorização do contexto educacional africano.

\section{Considerações finais}

Ao longo deste artigo, analisamos imagens de sala de aula com o objetivo de averiguar como são construídas as relações de interação entre o leitor/observador (PI) e os elementos representados em uma imagem (PR) e como os elementos semióticos da metafunção 
composicional interagem para construir o texto no modo visual. As imagens analisadas fazem parte de uma Unidade de LDLI cujo tópico é a vida escolar. Os resultados de nosso estudo corroboram o que diferentes estudiosos da GDV têm demonstrado e é atestado pelas palavras de Almeida (2009, p. 53): "as imagens são textos potencialmente imbuídos de significados e [...] precisam ser alçadas à condição de visibilidade no contexto educacional”. Ao dar visibilidade para os valores, ideologias e preconceitos veiculados pelo texto imagético, entendemos que nosso estudo pode contribuir para as práticas de letramento visual, especialmente para a formação de professores no sentido de demonstrar que imagens são textos que possuem uma estrutura sintática que pode ser ensinada nas aulas de língua inglesa.

Adicionalmente, nosso estudo aponta que as práticas pedagógicas com o texto imagético a partir dos pressupostos da GDV têm potencial para desconstruir significados ideológicos, crenças e valores que circulam no contexto social em que os alunos, consumidores desses textos, estão inseridos. Nesse sentido, cabe ao professor incorporar a leitura do texto imagético nas práticas pedagógicas de inglês como língua estrangeira no contexto da Educação Básica. Apontamos ainda que estudos sobre as imagens presentes em livros-didáticos revestem-se de importância, tendo em vista que esse material é o mais empregado e possivelmente o único recurso de que dispõem os professores de inglês na escola pública. Entendemos que a exploração e a discussão dos significados realizados no texto imagético têm grande potencial para instruir os alunos com relação aos valores e representações sociais que circulam na sociedade.

A gradação e hierarquização que apresentamos na comparação das imagens no escopo deste artigo tiveram como base os pressupostos da GDV, contudo é importante notar que a análise aqui empreendida também é permeada pela interpretação das analistas.

\section{REFERÊNCIAS}

ALMEIDA, Danielle Barbosa Lins. (Org.) Perspectivas em análise visual do fotojornalismo ao blog. João Pessoa: Ed. Universitária, 2008.

ALMEIDA, Danielle Barbosa Lins. Do texto às imagens: as novas fronteiras do letramento visual. In: PEREIRA, Regina Celi; ROCA, Pilar. (Orgs.). Linguística aplicada: um caminho com diferentes acessos. São Paulo: Contexto, 2009. p. 173-202.

ALMEIDA, Danielle Barbosa Lins. Pelos caminhos do Letramento Visual: Por uma proposta multimodal de leitura crítica de imagens. Revista Linguagem em Foco, Fortaleza, v. 3, n. 5, p. 43-64, 2011. 
ARAÚJO, Rosilma Diniz. Gramática visual: trazendo à visibilidade imagens do livro didático de LE. Signum: Estud. Ling., Londrina, v. 2, n. 14, p. 61-84, 2011.

BAMFORD, Anne. The visual literacy white paper. [Australia]: 2009. Disponível em: http://www.adobe.com/uk/education/pdf/adobe_visual_literacy_paper.pdf. Aceso em: 15 mar. 2021.

BARBOSA, Vânia Soares; ARAÚJO, Antonia Dilamar. Multimodalidade e Letramento Visual: um estudo piloto de atividades de leitura disponíveis em sítio eletrônico. Revista da Anpoll, Florianópolis, v. 1, n. 37, p. 17-36, jul/dez 2014.

CARVALHO, Sâmia Alves; ARAGÃO, Cleudene de Oliveira. Os caminhos do letramento visual: uma análise de material didático virtual. Revista Estudos Anglo-Americanos, Florianópolis, n. 44, p. 9-35, 2015.

FERREIRA, Aparecida de Jesus. CAMARGO, Mabia. O racismo cordial no livro-didático de língua inglesa aprovado pelo PNLD. Revista da $A B P N$, Guarulhos, v. 6, n. 12, p. 177-202, nov. 2013-fev. 2014.

FERREIRA, Isabella Bach. Textos multissemióticos e novas habilidades de leitura: contribuições para a formação docente. 2019. 92 f. Dissertação (Mestrado em Educação) Curso de Pós-Graduação em Educação, Universidade Federal de Lavras, Lavras, 2019.

FRANCO, Cláudio de Paiva; TAVARES, Kátia Cristina do Amaral. Way to English for Brazilian Learners. São Paulo: Editora Ática, 2015.

HALLIDAY, Michael. Language as social semiotic: the sociological interpretation of language and meaning. London: Edward Arnold, 1978.

HALLIDAY Michael. An introduction to functional grammar. London: Edward Arnold, 1985.

HALLIDAY, Michael; MATTHIESSEN, Christian. An introduction to functional grammar. $3^{\text {rd }}$ ed. London: Edward Arnold, 2014.

HARRISSON, Claire. Visual social semiotics: understanding how still images make meaning. Technical Communication, [s. l.], v. 50, n. 1, p. 46-60, Feb. 2003.

HOLANDA, Maria Eldelita Franco. A multimodalidade no CD-ROM Interchange third edition: uma investigação à luz da gramática do design visual. 2013. 218 f. Tese (Doutorado em Linguística) - Universidade Federal de Pernambuco, Recife, 2013.

JORGENS, Denise. Análise de imagens no livro didático de inglês como recurso de interação em sala de aula. 2018. 104 f. Dissertação (Mestrado em Letras) - Universidade Federal de Santa Maria, Santa Maria, 2018.

KRESS, Gunther; VAN LEEUWEN, Theo. Reading images: the grammar of visual design. London; New York: Routledge, 2006. 
KUMMER, Daiane Aline. Letramento multimodal crítico: sob a perspectiva de livros didáticos e de professores de inglês e biologia. 2015. 149 f. Dissertação (Mestrado em Letras) - Universidade Federal de Santa Maria, Santa Maria, 2015.

LAKATOS, Eva Maria; MARCONI, Maria de Andrade. Metodologia do trabalho científico: procedimentos básicos, pesquisa bibliográfica, projeto e relatório, publicações e trabalhos científicos. 4 ed. São Paulo: Atlas, 1992.

LOVATO, Cristina dos Santos. Análise das imagens em notícias de popularização científica. Revista Travessias, Cascavel, v. 4, n. 3, p. 114-133, 2010.

MÜLLER, Tânia Mara Pedroso. A produção acadêmica sobre o negro no livro-didático: estado do Conhecimento (2003-2013). 37 ${ }^{a}$. Reunião Nacional da Anped - 04 a 08 de outubro de 2015, Florianópolis, 2015. Disponível em:

https://www.anped.org.br/biblioteca/item/producao-academica-sobre-imagem-do-negro-nolivro-didatico-estado-do-conhecimento. Acesso em: 12 mar. 2021.

OLIVEIRA, Sara. Texto visual e leitura crítica: o dito, o omitido, o sugerido. Linguagem e Ensino, Pelotas, v. 9, n. 1, p. 15-39, jan./jun. 2006.

SHOHAT, Ella; STAM, Robert. Crítica da imagem eurocêntrica: multiculturalismo e representação. São Paulo: Cosac e Naify, 2006.

SILVA, Mônica Maria Pereira da; ALMEIDA, Danielle Barbosa Lins. Linguagem verbal, linguagem visual: reflexões teóricas sobre a perspectiva sócio-semiótica da linguística sistêmico-funcional. Odisséia, Natal, v. 3, n. 1, p. 36-56, jan./jun. 2018.

SILVA, Flávia Carolina. Análise da representação do/a negro/a em um livro didático. Revista Africa e Africanidades, [s. l.], ano 8, n. 20, jul. 2015.

SILVA, Maria Zenaide Valdivino da. O letramento multimodal crítico no ensino fundamental: investigando a relação entre a abordagem do livro didático de língua inglesa e a prática docente. 2016. 329 f. Tese (Doutorado)- Universidade Estadual do Ceará, 2016.

Artigo submetido em: 28 abr. 2021

Aceito para publicação em: 23 jun. 2021

DOI: http://dx.doi.org/10.22456/2238-8915.113455 